\title{
BASIC ENGINEERING MECHANICS
}


Other titles of interest to engineers

An Introduction to Engineering Fluid Mechanics

J. A. Fox

Principles of Engineering Thermodynamics

E. M. Goodger

Analysis and Presentation of Experimental Results

R. H. Leaver and T. R. Thomas

A Background to Engineering Design

Peter Polak

Mechanics of Machines

G. H. Ryder and M. D. Bennett

Essential Solid Mechanics - Theory, worked examples and problems B. W. Young 


\title{
BASIC ENGINEERING MECHANICS
}

\author{
J.H.HUGHES \\ K.F. MARTIN \\ Department of Mechanical Engineering \\ and Engineering Production, UWIST
}


๑ J. H. Hughes and K. F. Martin 1977

All rights reserved. No part of this publication may be reproduced or transmitted, in any form or by any means without permission.

First published 1977 by

THE MACMILLAN PRESS LTD

London and Basingstoke Associated companies in New York Dublin Melbourne Johannesburg and Madras

ISBN 978-1-349-02451-3 ISBN 978-1-349-02449-0 (eBook)

DOI 10.1007/978-1-349-02449-0

This book is sold subject to the standard conditions of the Net Book Agreement.

The paperback edition of this book is sold subject to the condition that it shall not, by way of trade or otherwise, be lent, resold, hired out, or otherwise circulated without the publisher's prior consent in any form of binding or cover other than that in which it is published and without a similar condition including this condition being imposed on the subsequent purchaser. 


\section{Contents}

Preface $\quad$ ix

1 Introduction 1

1.1 Concept: Postulate: Law 1

1.2 Dimensions and Units 2

1.3 Statics and Dynamics 3

1.4 Mathematical Considerations 4

2 Fundamentals 5

2.1 Particle: Rigid Body: System 5

2.2 Scalars and Vectors 6

2.3 Addition of Vectors 6

2.4 Components and Unit Vectors 8

$\begin{array}{lll}2.5 & \text { Units } & 10\end{array}$

2.6 Solution of Problems 11

3 Statics of a Particle 13

$\begin{array}{lll}3.1 & \text { Resultant: Components } & 13\end{array}$

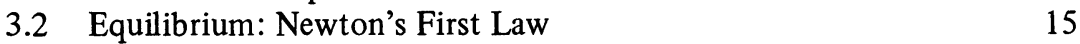

$\begin{array}{ll}3.3 \text { Conditions for Equilibrium } & 15\end{array}$

$\begin{array}{ll}3.4 & \text { Applications } \\ 3.5 & 16\end{array}$

$\begin{array}{lll}3.5 & \text { Summary } & 18\end{array}$

$4 \quad$ Statics of Rigid Bodies $\quad 21$

$\begin{array}{lll}4.1 & \text { Newton's Third Law } & 21\end{array}$

4.2 Principle of Transmissibility 22

4.3 Resultant: Parallel Forces: Couples 22

4.4 Centre of Parallel Forces 24

4.5 Moment of a Force 25

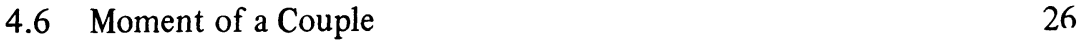

4.7 Force-Couple Sets 27

4.8 Coplanar Forces: Resultant 28

4.9 Conditions for Equilibrium 30

4.10 Solution of Problems 31

4.11 Composite and Connected Bodies 33

4.12 Simple Trusses $\quad 37$

4.13 Simple Frames $\quad 40$

4.14 Summary $\quad 47$ 
5 Friction $\quad 57$

$\begin{array}{lll}5.1 & \text { Characteristics of Dry Friction } & 57\end{array}$

5.2 Some Practical Applications $\quad 67$

$\begin{array}{lll}5.3 & \text { Summary } & 83\end{array}$

6 Virtual Work 91

$\begin{array}{lll}6.1 & \text { Work } & 91\end{array}$

6.2 Principle of Virtual Work 93

6.3 Applications: Connected Bodies 94

6.4 Connected Bodies: Friction and Elastic Members 96

6.5 Systems with Two Degrees of Freedom 98

$\begin{array}{lll}6.6 & \text { Summary } & 100\end{array}$

7 Centres of Gravity and of Mass: Centroids 104

$\begin{array}{lll}7.1 & \text { Centre of Gravity } & 104\end{array}$

7.2 Centres of Gravity: Standard Cases 107

$\begin{array}{ll}7.3 \text { Centre of Mass } & 112\end{array}$

$\begin{array}{lll}7.4 & \text { Centroids of Lines, Surfaces and Volumes } & 113\end{array}$

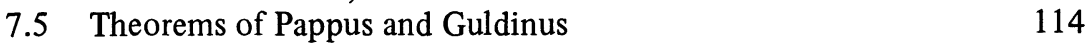

$\begin{array}{lll}7.6 & \text { Summary } & 118\end{array}$

8 Kinematics of a Particle 123

$\begin{array}{lll}8.1 & \text { Rectilinear Motion of a Particle } & 123\end{array}$

8.2 Curvilinear Motion of a Particle 134

$\begin{array}{ll}\text { 8.3 Angular Motion of a Line } & 143\end{array}$

8.4 Simple Harmonic Motion $\quad 145$

8.5 Relative Motion of Particles 148

$\begin{array}{llr}\text { 8.6 Summary } & 159\end{array}$

9 Kinetics of Particles and Particle Systems I - Equations of Motion 164

$\begin{array}{lll}9.1 & \text { Equations of Motion for a Particle } & 164\end{array}$

$\begin{array}{ll}\text { 9.2 Equations of Motion for a Particle System } & 170\end{array}$

$\begin{array}{ll}\text { 9.3 Solution of Problems } & 174\end{array}$

$\begin{array}{ll}\text { 9.4 Connected Particles } & 175\end{array}$

$\begin{array}{lll}9.5 \text { Summary } & 179\end{array}$

10 Kinetics of Particles and Particle Systems II - Integrated Forms 185

$\begin{array}{ll}10.1 \text { Linear Impulse and Linear Momentum } & 186\end{array}$

$\begin{array}{ll}10.2 \text { Conservation of Linear Momentum } & 190\end{array}$

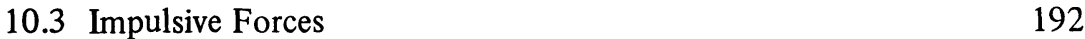

$\begin{array}{ll}10.4 \text { Impact } & 192\end{array}$

10.5 Work and Kinetic Energy 203 
10.6 Evaluation of Work in Standard Cases 209

10.7 Potential Energy and Conservative Forces 213

$\begin{array}{ll}10.8 \text { Extraneous Forces } & 216\end{array}$

$\begin{array}{ll}10.9 \text { Summary } & 220\end{array}$

11 Kinematics of Rigid Bodies 226

11.1 Types of Rigid Body Motion 226

$\begin{array}{ll}\text { 11.2 Instantaneous Centre of Rotation } & 232\end{array}$

$\begin{array}{ll}11.3 \text { Engineering Applications } & 236\end{array}$

$\begin{array}{ll}11.4 \text { Velocity and Acceleration Diagrams } & 242\end{array}$

$\begin{array}{ll}11.5 & \text { Analytical Methods } \\ 11.6 & 248\end{array}$

$\begin{array}{ll}11.6 \text { Summary } & 252\end{array}$

12 Moments of Inertia 262

12.1 Moment of Inertia and Radius of Gyration 262

$\begin{array}{ll}\text { 12.2 Theorems } & 262\end{array}$

$\begin{array}{lll}12.3 & \text { Standard Forms } & 268\end{array}$

12.4 General Method for Calculating I for Complex Bodies 274

$\begin{array}{lll}12.5 \text { Summary } & 278\end{array}$

13 Kinetics of a Rigid Body 283

$\begin{array}{lll}13.1 & \text { Equations of Motion } & 283\end{array}$

$\begin{array}{ll}\text { 13.2 Impulse and Momentum } & 295\end{array}$

$\begin{array}{ll}13.3 \text { Work and Energy } & 312\end{array}$

13.4 Problems Involving Friction $\quad 325$

$\begin{array}{ll}13.5 \text { Composite Problems } & 332\end{array}$

$\begin{array}{lll}13.6 & \text { Summary } & 338\end{array}$

$\begin{array}{ll}\text { Appendix } & 351\end{array}$

Answers to Problems 355

$\begin{array}{ll}\text { Index } & 361\end{array}$ 


\section{Preface}

The aim of this text is to present a systematic development of elementary applied mechanics assuming a mathematical background of elementary algebra, geometry and calculus. A knowledge of the principles of Newtonian mechanics is fundamental to the solution of many engineering problems and is a prerequisite for the study of more advanced texts; it is hoped that the treatment here will provide sufficient material on which this knowledge can be based.

Our experience leads us to believe that a return to basic principles is often desirable, and is particularly necessary for new engineering undergraduates who, in spite of having been exposed to previous instruction, frequently display a lack of familiarity with the meaning and significance of certain basic ideas. It is to this category that the book is mainly addressed, namely first-year students studying for an engineering degree or equivalent, who have some acquaintance with the subject matter but who require a more thorough grounding. The book is designed to cover the applied-mechanics content of the first year of an engineering degree course but will, in many cases, also provide a significant contribution to the second-year syllabus in mechanics of machines.

The traditional subdivision into statics and dynamics has been retained in order that familiarity may initially be gained with forces and their manipulation. We do not wish to appear pedantic in this matter since we recognise that there may be an equally good case for placing the initial emphasis on the concept of mass. Unfortunately it is difficult at this elementary level to treat one without the other, and a choice has to be made.

Having expressed Newton's laws in terms of particle behaviour the development of both statics and dynamics proceeds by way of particle systems to rigid bodies and systems of rigid bodies, incorporating in some cases a limited number of elastic elements.

In order to keep the discussion within reasonable bounds certain topics have been purposely omitted in the knowledge that detailed treatments are available elsewhere. For example, a more comprehensive study of the methods of structural analysis is better left to those books devoted to this topic. More important is the limitation of the discussion in the main to topics in two dimensions. This is in accord with the elementary nature of the book, but the decision.was also based on the belief that the extension to three dimensions is facilitated by a thorough grounding in the basic principles that we hope this book will provide.

The inertia-force method of solution is given prominence for dealing with problems involving acceleration. Objection is raised by many, whose views we respect, on the grounds that the method is of historical interest only, and that it is used to assist in solving problems whose solution using dynamical principles requires no such assistance. We do not think these objections are completely valid; we maintain that the method has its merits and does nothing to relieve the student of the necessity of fully understanding the dynamics of the problem. 
Our justification for writing yet another book on applied mechanics is that we felt there was a gap between those of very elementary nature and the more comprehensive texts that give rather more coverage than we considered necessary at this level, and that this gap could be filled by a book based on elementary mathematical knowledge but in which the argument was carefully developed. Also, by imposing the limitations already mentioned, we hope that the book will be within the financial reach of the student we wish to address. With these considerations in mind we claim no originality for the subject matter, the principles of which have long been recognised. However, we hope that the presentation, including the worked examples, chapter summaries and hints to problems, will be found of direct assistance to the student.

The book is separated into thirteen chapters with sections and subsections identified by a decimal notation; for example, 2.3.4 refers to subsection 2.3.4 in chapter 2 . Equations relating to the text also carry a decimal notation and are numbered consecutively through each chapter; for example, the fifth equation in chapter 2 is numbered 2.5. Figure numbers again use the decimal notation and are numbered consecutively through each chapter including those relating to worked examples and problems. Answers to problems are assembled at the back of the book in the hope that students will exercise some restraint before consulting these.

We wish to acknowledge the encouragement of several colleagues in making comments on certain chapters, also the unstinting help of our typists, in particular Mrs Wilma Scott. 